\title{
Ausserordentliche Ärztekammersitzung
}

Samstag, 11. Oktober 2003, Solothurn

\section{Reihenfolge}

- Nicht behandelte Traktanden der Ärztekammer vom 30. April 2003.

- Spätestens um 14.00 Uhr werden die zu diesem Zeitpunkt diskutierten Traktanden unterbrochen, um Traktandum 5, KVG-Referendum, zu beraten.

- Weitere Traktanden werden der Reihe ihres Eintreffens nach an die bereits bestehende Traktandenliste angehängt.

\section{Tagesordnung}

1. Begrüssung, Mitteilungen Bestellung des Büros (Art. 4.2 Geschäftsordnung FMH)

2. TARMED (Traktandum vom 30. April 2003)

a) Dignitätserhebung

b) Delegierte Psychotherapie

c) Reengineering II

3. Weiterbildung

(Traktandum vom 30. April 2003)

1. Schaffung von Fähigkeitsund Fertigkeitsausweisen

a) Schaffung des Fertigkeitsausweises «Gastroskopie»

b) Schaffung des Fertigkeitsausweises «Endoskopische retrograde CholangioPankreatographie ERCP»

2. KWFB: Einsitznahme neuer Gesellschaften

a) APPM (Akademie für Psychosomatische und Psychosoziale Medizin)

b) SMSH (Schweizerische Ärztegesellschaft für Hypnose)

3. Revision der Weiterbildungsordnung

4. Umgang mit Tätern

(Traktandum vom 30. April 2003)
5. KVG

Beschluss über ein allfälliges Referendum der FMH zur 2. Revision des KVG

6. LOMA (Leistungsorientierte Medikamentenabgabe im Arztkanal): Verhandlungsdelegation

7. Weitere TARMED-Anträge

8. Varia

\section{Teilnehmer}

Die gewählten Delegierten der Gesellschaften oder ihre gewählten Stellvertreter sind bis spätestens 9. Oktober 2003, 18.00 Uhr, dem Generalsekretariat zu melden. Sie erhalten im Tagungsbüro gegen Vorlage eines identifizierenden Ausweises, am besten des Mitgliederausweises der FMH, einen Badge, der für Zutritt und Stimmabgabe berechtigt.

Ein Austauschen der Badges oder eine Weitergabe derselben ist nicht zulässig.

FMH-Mitglieder, die an der Sitzung teilnehmen wollen, erhalten beim Tagungsbüro gegen Vorweisen des Mitgliederausweises einen Badge, der für den Zutritt ohne Recht zur Stimmabgabe berechtigt.

Vom ZV eingeladene Nichtmitglieder, die an der Ärztekammersitzung teilnehmen müssen, erhalten ebenfalls gegen Vorlage eines identifizierenden Ausweises beim Tagungsbüro einen Zutrittsbadge.

Die Zutrittskontrolle wird durch zwei Sicherheitsbeauftragte vorgenommen. Sie sind angewiesen, nur Personen mit Badges den Zutritt zu gewähren und Personen wegzuweisen, die sich nicht an die vorgenannten Regelungen halten. 


\section{Séance extraordinaire de la Chambre médicale}

Samedi 11 octobre 2003, Soleure

\section{Succession des points à l'ordre du jour}

- Objets non traités lors de la Chambre médicale du 30 avril 2003.

- La discussion sur ces objets sera interrompue à $14 \mathrm{~h} 00$ au plus tard, afin de débattre du point 5: référendum LAMal.

- D'autres points éventuels seront ajoutés au présent ordre du jour dans l'ordre de leur réception.

\section{Ordre du jour}

1. Paroles de bienvenue, communications Désignation du Bureau de la séance (art. 4.2 du Règlement d'exécution de la FMH)

2. TARMED

(point à l'ordre du jour du 30 avril 2003)

a) Recensement de la valeur intrinsèque

b) Psychothérapie déléguée

c) Deuxième phase du remaniement (Reengineering II)

3. Formation postgraduée (point à l'ordre du jour du 30 avril 2003)

1. Création d'attestations de formation complémentaire et de certificats d'aptitude technique

a) certificat d'aptitude technique «Gastroscopie»

b) certificat d'aptitude technique «Cholangio-pancréatographie endoscopique rétrograde ERCP»

2. Droit de siéger à la CFPC: admission de nouvelles sociétés

a) AMPP (Académie pour la médecine psychosomatique et psychosociale)

b) SMSH (Société médicale suisse d'hypnose)

3. Révision de la Réglementation pour la formation postgraduée
4. Traitement des auteurs de délits (point à l'ordre du jour du 30 avril 2003)

\section{LAMal}

Décision quant à un éventuel référendum de la FMH concernant la deuxième révision de la LAMal

6. RBP (Rémunération des médicaments basée sur les prestations, dispensation par les médecins): délégation aux négociations

7. Autres propositions concernant le TARMED

8. Divers

\section{Participants}

Les délégués élus des sociétés, ou leurs remplaçants élus, doivent s'annoncer au Secrétariat général d'ici le 9 octobre 2003, à 18 h 00 au plus tard. Ils recevront le jour de la séance, contre une carte d'identification (de préférence la carte de membre de la FMH), un badge leur donnant le droit d'entrée et de vote.

Il ne saurait être question de remettre le badge à une tierce personne ou de l'échanger.

Les membres de la FMH qui souhaitent participer à la Chambre médicale recevront au Bureau de la séance un badge d'entrée sans droit de vote.

Les non-membres invités par le CC à participer à la Chambre médicale recevront au Bureau de la séance, également contre identification, un badge d'entrée.

Le contrôle d'entrée sera effectué par deux agents de sécurité. Ils seront chargés de n'admettre que les personnes munies d'un badge et de refuser l'entrée à celles qui ne se seraient pas tenues aux règles ci-avant. 